\title{
INNOVATION, SELECTION AND THE EMERGENCE OF TRANSPARENT SIGNALS IN INTERACTION
}

\author{
Seán G. Roberts ${ }^{1}$, Ashley Micklos ${ }^{2}$, Justin Sulik ${ }^{3}$, and Hannah Little ${ }^{4}$ \\ ${ }^{1}$ excd.lab, University of Bristol, UK, sean.roberts@bristol.ac.uk \\ ${ }^{2}$ Linguistics Department, University of California, San Diego, USA \\ ${ }^{3}$ Department of Psychology, Royal Holloway University of London, UK \\ ${ }^{4}$ Department of Applied Sciences, University of the West of England, Bristol, UK
}

We review recent work in interactive experimental semiotics to discuss how biases in innovation and selection during interaction lead to the cultural evolution of transparent signals.

Recent studies suggest that individuals are not good at innovating transparent signals. For example, Sulik and Lupyan (2016) show that there are large individual differences in perspective taking abilities, with most participants in communication games being poor at choosing a signal that will be easy for their partners to interpret (though there are 'rare geniuses'). Verhoef, Roberts, and Dingemanse (2015) found that iconic signals could take generations to emerge, even with only 4 meanings and where the stimuli were designed to have obvious iconic mappings. Tamariz et al. (2017) found that innovations are equally likely to increase or decrease iconicity. While studies such as Tamariz et al. (2014) find that transparent signals are innovated in early generations, there are large individual differences in the ability to do this (though see Ortega, Schiefner, \& Ozyurek, 2017; Schouwstra \& de Swart, 2014). This would make innovation random (unbiased). This is supported to some extent by cross-linguistic studies arguing that iconicity in the lexicon both increases and decreases over cultural evolutionary time (Blasi et al., 2016). Even classic examples of individual innovation of transparent signals such as 'universal' sentence structures of creoles have recently been called into question (Blasi et al., 2017). How, then, do transparent linguistic conventions emerge?

One answer is that interaction provides the key mechanisms. Interaction can be thought of as an independent level of cultural evolution. In the broad model of genetic evolution (Dawkins, 1982; Hull, 1980), the gene is a replicator and an organism is a vehicle that interfaces with the environment to allow the replicator to replicate. According to Croft (2000) this model also applies to language: the word or phrase is a replicator and the individual speaker is the vehicle. However, this misses out a level between the individual's brain and the spoken phrases: turns at talk (sequences) in conversational interaction. This is highlighted in Buyn et al. (2016) which studies signers converging on a shared lexicon. They find that 
frequency and transparency are good predictors of whether a form will survive, but that the type of sequence in which a form appears also matters. For example, a form produced in an explicit teaching sequence has a higher probability of surviving than a form produced in a simple statement. Several other studies also find that sequences such as repair can be loci of selection (Micklos, 2016) and can promote better communication in subsequent conversations (Mills \& Redeker, 2016; Macuch Silva et al., 2017). This suggests that conversational sequences are also vehicles, at a different level to the individual speakers. The type of sequence promotes (or inhibits) the replication of the phrases within it, just as a particular type of cell within an organism influences the replication of the genes within it.

Indeed, Micklos (2017) suggests that specific interactional sequences such as other-initiated repair can transform the innovation process. If a partner does not understand, they are motivated to produce a new variant, which are often more transparent (biased innovation). That is, participants do not devote large processing effort to producing transparent signals until they encounter a communication problem, after which they do engage in more effortful perspective taking. Since people are good at recognising transparent signals (Sulik \& Lupyan, 2016), once they arise they will be adopted and reproduced (Tamariz et al., 2014; Rogers \& Fay, 2016).

A slightly different answer is that innovation is random, but that interaction simply provides inherent feedback about signal transparency. After negative feedback, participants innovate a new signal, which may be adopted if it is effective. Indeed, Tamariz et al. (2017) find that innovation is random but selection during interaction is biased towards adopting transparent signals.

The two possibilities could be compared experimentally or by looking at emergence dynamics. Random innovation and biased selection should exhibit punctuated equilibrium, while biased innovation should exhibit more gradual change. In either case, this would shield individuals from needing to apply perspective taking constantly, perhaps explaining the variation in perspective taking ability.

\section{Acknowledgements}

Thanks to Elizabeth Irvine for comments. SGR supported by Leverhulme fellowship ECF-2016-435.

\section{References}

Blasi, D. E., Michaelis, S. M., \& Haspelmath, M. (2017). Grammars are robustly transmitted even during the emergence of creole languages. Nature Human Behaviour.

Blasi, D. E., Wichmann, S., Hammarström, H., Stadler, P. F., \& Christiansen, M. H. (2016). Sound-meaning association biases evidenced across thousands of languages. PNAS, 201605782. 
Byun, K.-S., Roberts, S. G., De Vos, C., Levinson, S. C., \& Zeshan, U. (2016). Content-biased and coordination-biased selection in the evolution of expressive forms in cross-signing. In Proceedings of the 7th International Society for Gesture Studies Conference, Paris, France.

Croft, W. (2000). Explaining language change. Harlow, Essex: Longman.

Dawkins, R. (1982). Replicators and vehicles. Current problems in sociobiology, $45,64$.

Hull, D. L. (1980). Individuality and selection. Annual review of ecology and systematics, 11(1), 311-332.

Macuch Silva, V., Roberts, S., Holler, J., \& Özyürek, A. (2017). An experimental study of multimodal communication and early language emergence. Proceedings of Protolang 5.

Micklos, A. (2016). Interaction for facilitating conventionalization: Negotiating the silent gesture communication of noun-verb pairs. In S. Roberts, C. Cuskley, L. McCrohon, L. Barceló-Coblijn, O. Fehér, \& T. Verhoef (Eds.), The evolution of language: Proceedings of the 11th international conference (evolangx11).

Micklos, A. (2017). Repair as a driver of innovation, improvement, and alignment in cumulative cultural evolution. In Proceedings of the Cultural Evolution Society Conference, Jena.

Mills, G., \& Redeker, G. (2016). Making invisible trouble visible: Self-repair increases abstraction of referring expressions. In Cogsci 38.

Ortega, G., Schiefner, A., \& Ozyurek, A. (2017). Speakers gestures predict the meaning and perception of iconicity in signs. In the 39th annual conference of the cognitive science society (cogsci 2017).

Rogers, S. L., \& Fay, N. (2016). Stick or switch: A selection heuristic predicts when people take the perspective of others or communicate egocentrically. PloS one, 11(7), e0159570.

Schlag, K. H. (1998). Why imitate, and if so, how? Journal of economic theory, 78(1), 130-156.

Schouwstra, M., \& de Swart, H. (2014). The semantic origins of word order. Cognition, 131(3), 431-436.

Sulik, J., \& Lupyan, G. (2016). Failures of perspective taking in an open-ended signaling task. In S. Roberts \& al. (Eds.), The evolution of language: Proceedings of the 11th international conference (evolangx11).

Tamariz, M., Ellison, T. M., Barr, D. J., \& Fay, N. (2014). Cultural selection drives the evolution of human communication systems. Proceedings of the Royal Society of London B: Biological Sciences, 281(1788), 20140488.

Tamariz, M., Roberts, S. G., Martínez, J. I., \& Santiago, J. (2017). The interactive origin of iconicity. Cognitive Science.

Verhoef, T., Roberts, S., \& Dingemanse, M. (2015). Emergence of systematic iconicity. In Cogsci 37 (p. 2481-2486). 